\title{
Línea Jurisprudencial: El derecho de los deportistas
}

Recibido: 10/02/2012 Aprobado: 13/04/2012

\section{INTRODUCCIÓN}

A partir de la promulgación de la actual Constitución Política colombiana, el principio fundamental de la Autonomía Universitaria se ha fortalecido, siendo un derecho que cada día se impone para hacer respetar las decisiones de las universidades en Colombia.

La Corte Constitucional como ente máximo protector de Derechos y Principios define cuales son los parámetros constitucionales y legales de esta autonomía, que permita su pleno disfrute sin vulnerar o amenazar derechos de terceros, como pueden ser los derechos de los deportistas.

Esta línea jurisprudencial busca establecer la forma como el alto tribunal constitucional ha ponderado los derechos constitucionales en disputa:de un lado el de los deportistas (Igualdad) y por el otro el de las Instituciones de Educación Superior (Autonomía Universitaria),en los casos en que se adjudican cupos especiales de ingreso a los Programas Académicos en las Universidades.

Por tal razón, el presente trabajo se focaliza en dos (2) puntos en contradicción: de una parte la autonomía y, de la otra, la igualdad, sin dejar de lado los sujetos involucrados como son los deportistas y las Universidades.
Martha Cecilia Abella de Fierro Decana de la Facultad de Derecho de la Universidad Surcolombiana

Sebastian Sepúlveda Lizcano

Estudiante de la Facultad de Derecho de la Universidad Surcolombiana

Los deportistas en Colombia son considerados una población primordial y esencial en el desarrollo social del país. Si bien sus derechos no tienen una consagración expresa en la Carta Política actual, su protección se da a través de la interpretación constitucional de otros derechos como la igualdad, lo cual ha permitido proteger el ingreso y la participación en espacios universitarios que les permita constituirse como profesionales integrales.

Por ello es importante la elaboración de una línea jurisprudencial sobre la concepción que se tiene en un Estado Social de Derecho frente a la inclusión del deporte en la vida universitaria y la viabilidad de ingresar a la Universidad en calidad de deportista, además de los otros requisitos fijados por ésta.

La línea jurisprudencial sobre el derecho de los deportistas es justificable en virtud de la necesidad de establecer la forma como la Corte Constitucional colombiana ha desarrollado su argumentación para responder el problema que se presenta ante la existencia de un enfrentamiento de los derechos de los deportistas y su ingreso a la Universidad, sin desconocer la Autonomía Universitaria, lo cual le permite a estas Instituciones de Educación Superior definir los requisitos para asignar los cupos de sus programas académicos bajo los parámetros de la Constitución Política y la Ley. 


\section{OBJETIVO GENERAL}

- Elaborar una línea jurisprudencial en el campo del derecho de los deportistas como población especial, y su ingreso a Programas Académicos de la Universidades.

\section{OBJETIVOS ESPECÍFICOS}

Determinar los límites constitucionales de la autonomía universitaria frente a las solicitudes de ingreso y admisión de aspirantes a sus programas Académicos.

- Establecer la normatividad legal realizada frente desarrollo del Derecho Constitucional de la Autonomía Universitaria.

- Identificar los alcances constitucionales y legales del principio de igualdad de las personas aspirantes a ingresar a una Universidad, en relación con la admisión de poblaciones especiales como los deportistas.

- Estudiar el desarrollo del proceso constitucional jurisprudencia y doctrina - de la Corte Constitucional sobre el Principio de la Autonomía Universitaria como un derecho de la universidad colombiana y el derecho a la lgualdad de las personas que aspiran ingresar a estos claustros de educación superior.

\section{PROBLEMAJURÍDICO}

¿LAS UNIVERSIDADES COLOMBIANAS

DENTRO EL MARCO DE SU AUTONOMIA CONSTITUCIONAL PARA EXPEDIR SUS PROPIOS ESTATUTOS Y REGLAMENTOS, AL MOMENTO DE ADJUDICAR CUPOS ESPECIALES A DEPORTISTAS EN SUS PROCESOS DE ADMISIÓN, VULNERAN O NO EL PRINCIPIO DE IGUALDAD FRENTE A LOS DEMAS ASPIRANTES?

\section{PRINCIPIOS Y DERECHOS CONSTITUCIONALES VINCULADOS CON LA PROBLEMÁTICA}

\section{- Autonomia universitaria:}

ARTICULO 69: "Se garantiza la autonomía universitaria. Las universidades podrán darse sus directivas y regirse por sus propios estatutos, de acuerdo conla ley.

La ley establecerá un régimen especial para las universidades del Estado.

El Estado fortalecerá la investigación científica en las universidades oficiales y privadas y ofrecerá las condiciones especiales para su desarrollo.

El Estado facilitará mecanismos financieros que hagan posible el acceso de todas las personas aptas a la educación superior."

\section{- Principio de igualdad:}

ARTICULO 13: "Todas las personas nacen librese iguales ante la ley, recibirán la misma protección y trato de las autoridades y gozarán de los mismos derechos, libertades y oportunidades sin ninguna discriminación por razones de sexo, raza, origen nacional o familiar, lengua, religión, opinión política o filosófica.

El Estado promoverá las condiciones para que la igualdad sea real y efectiva y adoptará medidas en favor de grupos discriminados o marginados.

El Estado protegerá especialmente a aquellas personas que por su condición económica, física o mental, se encuentren en circunstancia de debilidad manifiesta y sancionará los abusos o maltratos que contra ellas se cometan."

\section{- Deporte:}

ARTÍ́CULO 52: "El ejercicio del deporte, sus manifestaciones recreativas, competitivas $y$ autóctonas tienen como función la formación integral de las personas, preservar y desarrollar una mejor salud en el ser humano.

El deporte y la recreación, forman parte de la educación y constituyen gasto público social. 
Se reconoce el derecho de todas las personas a la recreación, a la práctica del deporte y al aprovechamiento del tiempo libre.
El Estado fomentará estas actividades e inspeccionará, vigilará y controlará las organizaciones deportivas y recreativas cuya estructura $y$ propiedad deberán ser democráticas."

\section{ESCENARIO CONSTITUCIONAL}

\section{Gráfica 1.}

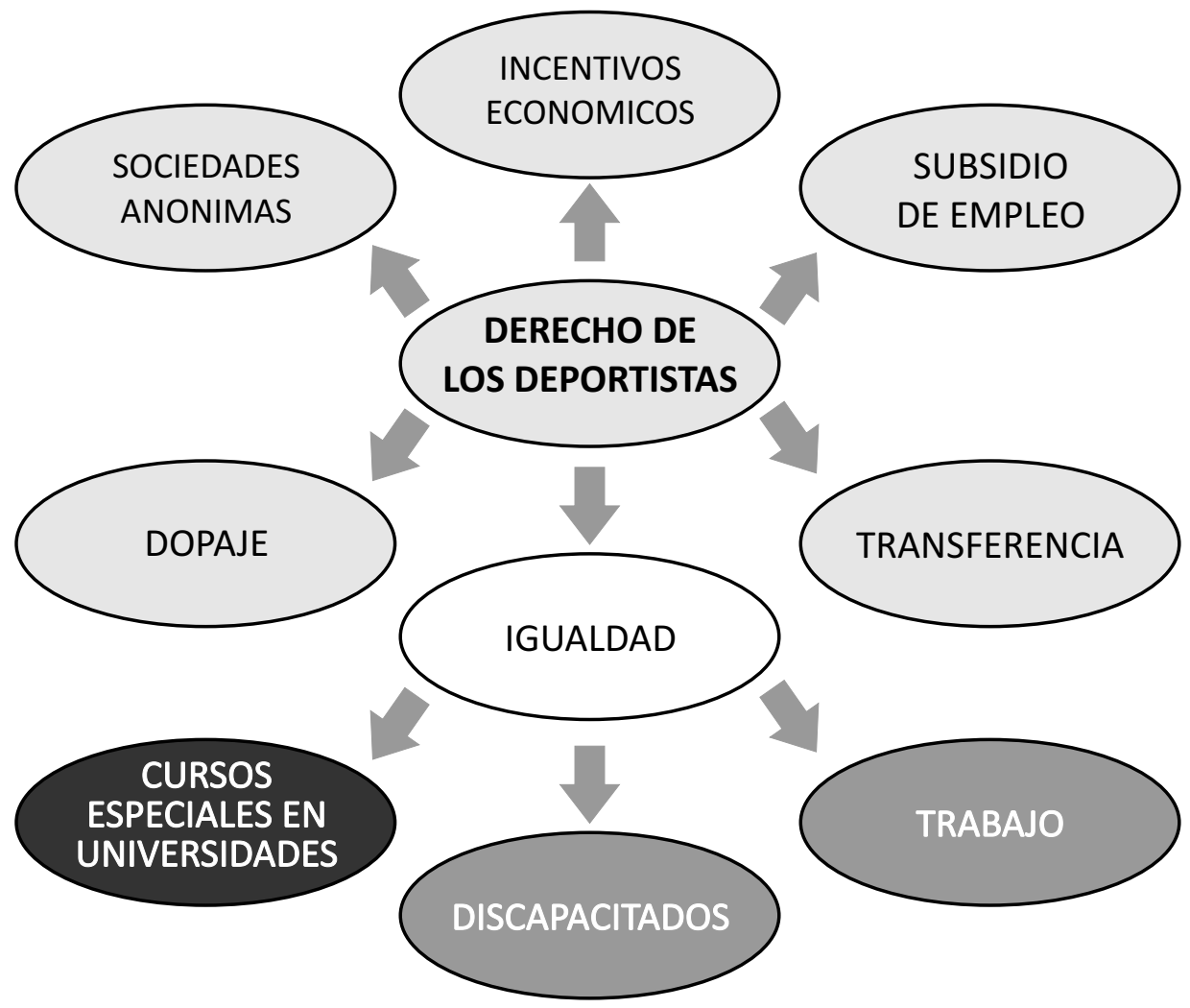

\section{ARGUMENTACIÓN DEL TEMA}

En lo que respecta al tema principal EL DERECHO DE LOS DEPORTISTAS, es fundamental precisar que no existe suficiente jurisprudencia de la Corte Constitucional que desarrolle los alcances y limitaciones, como sí sucede con otros derechos y principios. Pese a ello el deporte, en sus diferentes modalidades, no deja de ser importante para el día a día de Colombia, país por excelencia muy apasionado por las actividades deportivas tanto en su ejercicio como espectáculo.

Sin embargo, aunque el país es reconocido por su amor al deporte, no protege los derechos de los deportistas, quienes constantemente le entregan, en medallas de oro, plata y bronce, sus triunfos y reconocimientos internacionales esperando únicamente una respuesta de solidaridad tanto por su esfuerzo y sacrificio como por su constante superación. 
Frente a la jurisprudencia obtenida, se pueden observar algunos aspectos entre los que se destacan la igualdad de los deportistas paralímpicos y olímpicos, frente a la libertad de oficio. Es un tema, como ya se ha mencionado, no muy extenso pero con una gran cantidad de temática de principios constitucionales en juego.

\section{ARGUMENTACIÓN DEL ESCENARIO CONSTITUCIONAL}

Partiendo de la argumentación del tema central, la línea se enfoca desde la perspectiva de la autonomía universitaria pues es el derecho que puede llegar a enfrentarse con el derecho de los deportistas.

Por otro lado, siempre ha existido la inquietud de conocer los procedimientos que adelanta una universidad para seleccionar a sus estudiantes y la manera como se adjudican los cupos especiales, en este caso a los deportistas. Este es un asunto muy importante para la ponderación de derechos constitucionales como lo son el de la autonomía universitaria y el principio de igualdad desde la perspectiva de las admisiones de los aspirantes a obtener un cupo universitario.

\section{ARGUMENTO}

El problema jurídico planteado nace de la necesidad de conocer la jurisprudencia constitucionalista sobre los tres (3) puntos ya mencionados como lo es la autonomía universitaria, el principio de igualdad y el derecho de los deportistas.

Este es un problema meramente de principios constitucionales encaminado a determinar la imposición de uno sobre otro o simplemente la convivencia de los 2 en el ámbito de la educación superior. Al enfocarnos en el proceso de admisión de los estudiantes, es necesario establecer si los deportistas al tener un cupo independiente de los demás participantes estarían vulnerando la igualdad de oportunidades al ser tratados diferencialmente.

\section{Gráfica 2.}

\section{INGENIERÍA EN REVERSA}

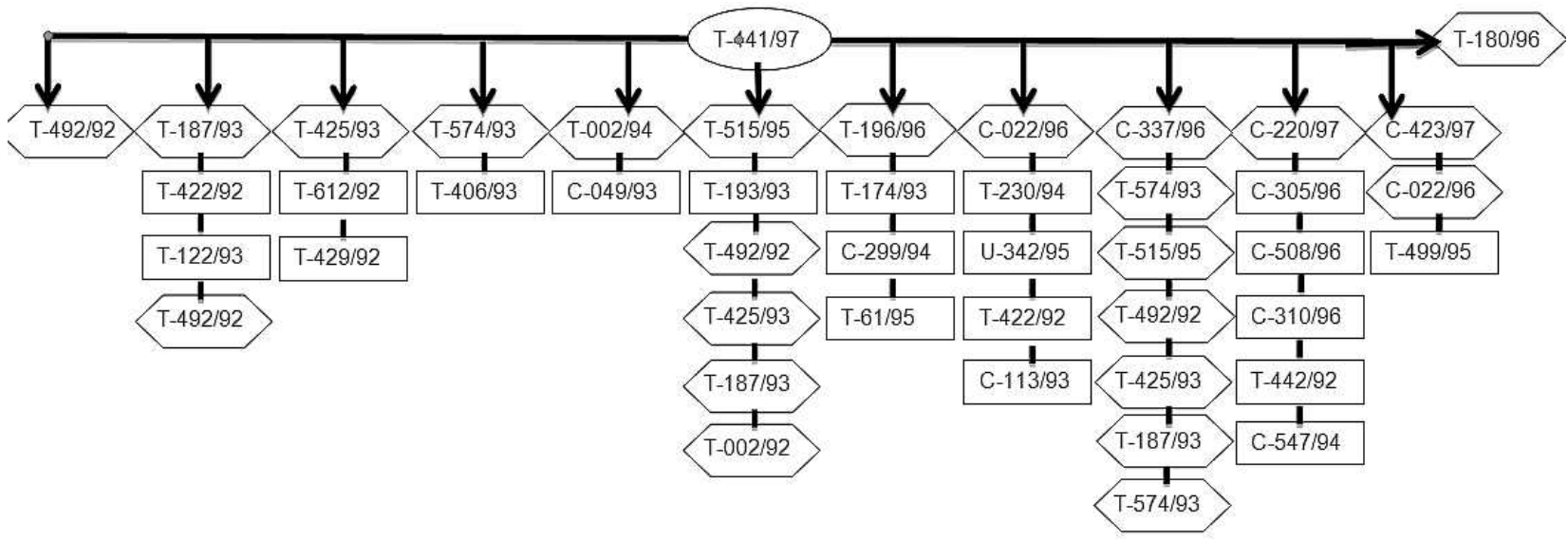

\begin{tabular}{|l|l|}
\hline \multicolumn{2}{|l|}{ CONVENCIONES } \\
\hline SENTENCIA ARQUIMEDICA & \\
\hline SENTECIAS QUE NO SIRVEN & \\
\hline SENTENCIAS QUE SIRVEN & \\
\hline
\end{tabular}


9. NICHO CITACIONAL

\begin{tabular}{|c|c|c|c|c|c|}
\hline 1992 & 1993 & 1994 & 1995 & 1997 & 1998 \\
\hline T-492 & T-187 & T-002 & T-018 & T-180 & T-441 \\
\hline & T-425 & & T-515 & T-196 & C-210 \\
\hline & T-374 & & & C-022 & C-220 \\
\hline & & & & C-337 & C-423 \\
\hline
\end{tabular}

\begin{tabular}{|l|l|}
\hline \multicolumn{2}{|l|}{ CONVENCIONES } \\
\hline SENTENCIA FUNDADORA \\
\hline SENTECIA ARQUIMEDICA \\
\hline SENTENCIA HITO
\end{tabular}

\section{BALANCE CONSTITUCIONAL}

\section{Gráfica 4.}

¿LAS UNIVERSIDADES COLOMBIANAS DENTRO EL MARCO DE SU AUTONOMIA CONSTITUCIONAL PARA EXPEDIR SUS PROPIOS ESTATUTOS Y REGLAMENTOS, AL MOMENTO DE ADJUDICAR CUPOS ESPECIALES A DEPORTISTAS EN SUS PROCESOS DE ADMISIÓN, VULNERA O NO EL PRINCIPIO DE IGUALDAD FRENTE A LOS DEMAS ASPIRANTES?

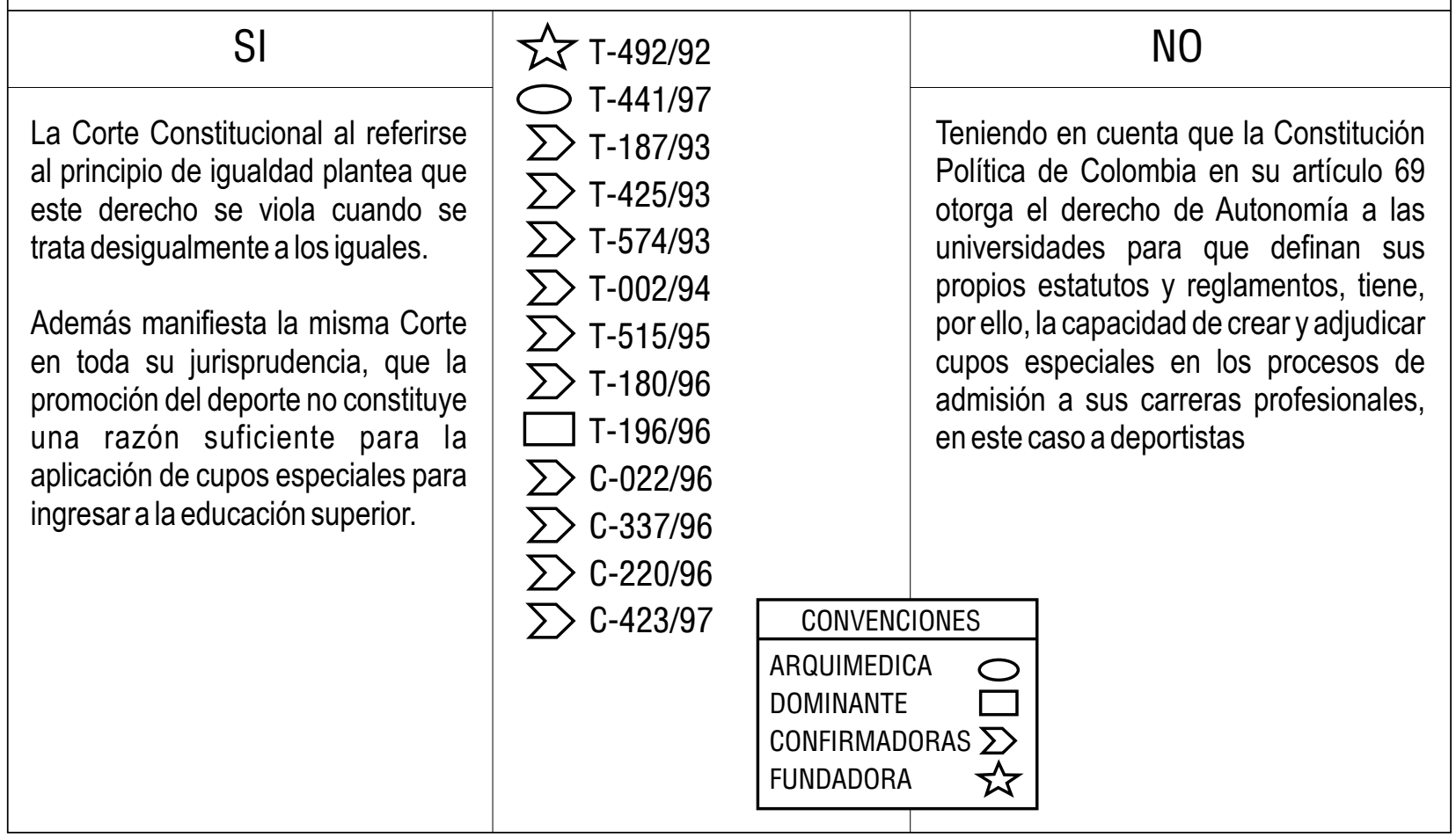




\section{NARRACIÓN}

Después de haber desarrollado todas las fases formales para construir la línea jurisprudencial, se procede ahora a la narración.

Analizadas cada una de las sentencias pertinentes al tema, se obtienen avances parciales (pueden venir más sentencias) sobre desatacados aspectos: Uno, el proceso administrativo de admisión y asignación de cupos que, en ejercicio de su autonomía, fijan las universidades colombianas para establecer las personas que ingresan a sus programas $y$, de manera específica, los cupos especiales en favor de los deportistas; dos, el relacionado a diferenciar el derecho a la autonomía de las universidades con el principio de igualdad de los aspirantes, para llegar al punto de convergencia entre ellos y por supuesto, como tercer aspecto, desarrollar el choque constitucional entre los derechos aludidos como fundamentales en un Estado Social de Derecho.

\subsection{De la autonomía universitaria}

Tratar la autonomía universitaria como derecho esencial de las universidades colombianas, conlleva evaluar el alcance del concepto de Estado Social de Derecho en la educación superior, si se tiene en cuenta que "El artículo 1 de la Constitución Política proclama que Colombia es un Estado Social de Derecho, esto es, un Estado democrático regulado por la ley, en el que priman los principios de igualdad, participación y pluralidad, y en el que el individuo se erige como epicentro de las acciones del Estado, las cuales serán legítimas en cuanto propendan por su bienestar y evolución, permitiéndole un desarrollo autónomo, singular e integral, el cual logra en la medida en que pueda, efectivamente, realizar sus derechos fundamentales" (Corte Constitucional Sentencia C-220 de 1997). Debemos señalar que el Estado colombiano por su carácter prestacional, debe velar por la aplicación y la garantía de los derechos fundamentales plasmados en el bloque de constitucionalidad; por ello es indispensable que los poderes públicos en Colombia estén encaminados, como en este caso, a hacer efectivo el cumplimiento tanto del derecho a la educación como el de la autonomía universitaria.

El tema implica también, analizar la labor del legislador frente a la protección de todos los derechos fundamentales, entre ellos la educación y la autonomía universitaria, la recreación y el deporte. Por ello la Corte Constitucional, en su jurisprudencia ha planteado que le corresponde al Estado "regular y ejercer la suprema inspección y vigilancia de la educación con el fin de garantizar el adecuado cubrimiento del servicio y asegurar las condiciones necesarias para elacceso de los estudiantes y su permanencia en el sistema educativo," (Sentencia T002 de 1994).

Este apartado jurisprudencial deja en evidencia la relación entre la concepción de Estado Social de Derecho y la efectividad de los derechos fundamentales, donde el Estado, como máximo garante de estos, debe ejercer la inspección y vigilancia mas no la intromisión en temas meramente encaminados a su autonomía y libre desarrollo. La citada Sentencia T-002 de 1994 señala el papel fundamental que tiene el legislador al momento de expedir leyes dirigidas a garantizar la protección de los derechos, cuando estatuye "El papel del legislador en la materia es bien importante, ya que es en las normas legales en donde se encuentran los límites de la señalada autonomía, a efecto de que las universidades no se constituyan en islas dentro del sistema jurídico". Es aquí donde la autonomía universitaria encuentra su desarrollo y limites, de tal manera que su goce no conlleve a constituir un sistema jurídico diferente (universidad), frente a lo ya estipulado en la Constitución Política.

Por eso la Ley 30 de 1992 al desarrollar este principio constitucional deja en claro los alcances de la autonomía universitaria:

"ARTICULO 28, Designar sus autoridades académicas y administrativas, crear, organizar y desarrollar sus programas académicos, definir y organizar sus labores formativas, académicas, docentes, cientificas y culturales, otorgar los títulos 
correspondientes, seleccionar a sus profesores, admitir a sus alumnos y adoptar sus correspondientes regímenes y establecer, arbitrar y aplicar sus recursos para el cumplimiento de su misión social y de su función institucional". (Subrayado es nuestro)

El desarrollo jurisprudencial de la Corte Constitucional es enfática en sostener que la autonomía universitaria no es plena ni absoluta y así lo señala en su Sentencia T-187 de 1993 cuando indica que "Los límites al ejercicio de la autonomía universitaria están dados en dos órdenes:

1. En el orden constitucional: pues el conjunto de disposiciones reglamentarias adoptadas por el centro educativo y en la aplicación de los mismos encuentra límite en la Constitución, en los principios y derechos que esta consagra, en las garantías que establece y en los mandatos que contiene.

2. En el orden legal: la misma Constitución en el inciso $1^{\circ}$ del artículo 69, dispone que las universidades podrán darse sus directivas y regirse por sus propios estatutos, de acuerdo con la ley."

Conforme con lo expuesto, queda claro que la autonomía universitaria, en el marco de la ley, permite a las Universidades fijar sus propios estatutos y reglamentos, sin que ello conlleve a vulnerar derechos fundamentales de terceros. En el ejercicio de esta autonomía, como derecho constitucional, le es viable a las instituciones de educación superior establecer los procedimientos administrativos de inscripción, admisión e ingreso de personas a sus programas académicos.

El articulo 69 superior, inciso final, impone a las universidades la necesidad de regirse por la ley y lo propuesto por otros principios constitucionales. Por ello como lo plantea la Corte Constitucional en la Sentencia C-220 de 1997 "Los límites a esa libertad de acción le corresponde establecerlos al legislador a través de la ley, obviamente cuidando de que ellos no se extiendan hasta desvirtuar el principio de autonomía o impedir su ejercicio por parte de las instituciones, ya, por las circunstancias particulares que los afectan, pues unas $u$ otras hacen imperativo que, con base en criterios proporcionados a aquellas, el Estado procure el equilibrio, cuyo sentido en Derecho no es otra cosa que la justicia concreta". El Estado como ente superior debe vigilar a través de sus instituciones la no violación de este principio y garantizar su pleno disfrute.

\subsection{Derechoa la igualdad}

Ahora bien, en uso de la autonomía, a las Universidades les corresponde el deber de respetar los derechos fundamentales de las personas. Tal es el caso del derecho a la igualdad. Este consagra la obligación de tratar en iguales términos a quienes se encuentren en una misma condición, sea cual fuere esta.

El principio de la lgualdad está consagrado en el artículo 13 de la Constitución Política y desarrollado ampliamente por la Corte Constitucional. La Sentencia T - 002 de 1994 sobre el tema señala "La igualdad exige el mismo trato para los entes e hechos que se encuentran cobijados bajo una misma hipótesis y una distinta regulación respecto de los que presentan características desiguales, bien por las condiciones en medio de las cuales actúan, ya por las circunstancias particulares que los afectan, pues unas y otras hacen imperativo que, con base en criterios proporcionados a aquellas, el Estado procure el equilibrio, cuyo sentido en derecho no es otra cosa que la justicia concreta"

De igual manera la jurisprudencia constitucional Colombiana ha definido parámetros que están dirigidos a promover su ejercicio y disfrute, como se puede observar en lo plasmado por la Sentencia No. C-022 de 1996:

a. "Si no hay ninguna razón suficiente para la permisión de un tratamiento desigual, entonces está ordenado un tratamiento igual.

b. Si hay una razón suficiente para ordenar un tratamiento desigual, entonces está ordenado un tratamiento desigual" 
Según estos lineamientos queda claro que para manejar un tratamiento desigual debe existir siempre una razón suficiente que conlleve este trato.

En lo concerniente al caso en concreto frente al problema jurídico planteado en el presente trabajo, se debe establecer que siendo la universidad un instrumento para la consecución de un proyecto de vida de los seres humanos, ello genera que muchas personas con sueños e ilusiones converjan en este escenario.Por ello, a la luz de la realidad, al ser Colombia un país con un atraso grandísimo en materia de educación superior, convierte cada cupo estudiantil en un bien escaso en relación con la gran demanda para acceder a este.

Por ello es importante aceptar la postura de la Corte Constitucional en la Sentencia C-423 de 1997 que afirma "La aplicación del principio de igualdad consagrado en el artículo 13 de la Constitución adquiere connotaciones especiales cuando, como en el caso colombiano, los recursos, bienes o medios a distribuir por parte del Estado son muy inferiores a la demanda social existente, es decir, cuando se trata de repartir bienes escasos. En estas situaciones, la afirmación de que todas las personas interesadas tienen derecho a que el Estado les asigne un recurso o un bien, además de ser ilusoria, tendría efectos paralizadores sobre la actividad estatal, e incluso podría originar serios problemas de estabilidad política. Por eso se ha considerado que la exigencia que se deriva del principio de igualdad para estos estados de cosas se restringe a que todas las personas interesadas tengan iguales posibilidades de acceder al proceso de selección de los beneficiarios y puedan tener la certeza de que la distribución de los bienes se hará acatando los procedimientos establecidos".

\subsection{Relación entre el derecho a la autonomía universitaria y el derecho a la igualdad}

Se llega así al punto cumbre de esta línea jurisprudencial ya que teniendo en cuenta tanto la autonomía universitaria y el principio de igualdad, es viable desarrollar el problema jurídico frente a la admisión de las personas con trato diferencial, en este caso los deportistas y las personas que por mérito deberían acceder a estos centros educativos. El análisis inicia con los procedimientos fijados por la Universidad sobre las condiciones exigidas para la asignación de cupos de ingreso a sus programas académicos y los mecanismos de divulgación que permita a los interesados acceder a estos. Sobre al particular se trae a colación la Sentencia No. T-187 de 1993 la cual señala: "El centro educativo debe con anticipación dar a conocer a las personas interesadas en el ingreso, los requisitos para la admisión, así como la valoración para cada una de las pruebas".

A su vez la sentencia C-337 de 1996 en lo concerniente a los criterios de selección, indica que es fundamental reconocer "la necesidad, conveniencia y conformidad con el ordenamiento superior de establecer criterios de selección para la admisión de los estudiantes a la educación superior, siempre y cuando dichos criterios no conlleven evaluaciones ni apreciaciones subjetivas que consagren tratamientos discriminatorios, sino que por el contrario, garanticen a las personas el acceso o ingreso a las instituciones de educación superior en condiciones de igualdad objetiva". Esto conlleva que al momento desarrollar el proceso de admisión y asignación de los cupos universitarios, todos los aspirantes deben ser tratados como iguales, es decir "igual entre iguales".

Corroborando lo dicho en la sentencias citadas, la Corte Constitucional en el año de 1997, plantea además que en lo que respecta a las pruebas para el ingreso deben ser "un instrumento neutro que... significa que todas las personas que se someten a las pruebas se encuentran en igualdad de condiciones: en efecto, todas desconocen el contenido de las pruebas, todas deben absolver el mismo examen, todas tienen el mismo tiempo para resolver las preguntas, todas están sujetas a las mismas condiciones, etc. Por eso, se puede afirmar que los exámenes de admisión constituyen momentos de igualación de los individuos." 
El Estado colombiano para hacer efectivo el alcance del artículo 13 de la Constitución Política, ha dispuesto que todos los bachilleres se sometan a una prueba diseñada y aplicada por el Instituto Colombiano de Fomento a la Educación Superior (ICFES) con el fin de generar una igualdad frente al ingreso a la universidad. Sobre el particular consagra la Corte Constitucional en su Sentencia T 441 de 1997: "Las pruebas de Estado, o sus equivalentes del ICFES, persiguen medir los conocimientos y las aptitudes de los aspirantes a un cupo universitario, con el objeto de distribuir las escasas plazas disponibles entre los postulantes que obtengan las mejores calificaciones. "Estas disposiciones legales y jurisprudenciales buscan poner un punto de inicio cero para cada uno de los aspirantes a cupos universitarios, independientemente de sus desigualdades de origen.

Sin embargo, la universidad en uso de sus potestades constitucionales, en el marco de las limitaciones ya mencionadas, tiene la capacidad de poder adjudicar cupos especiales para el ingreso a sus programas y carreras, pero ello no significa desconocer el derecho a la igualdad, pues debe actuar bajo argumentos razonables y acorde a la realidad del país.

Para que la universidad pueda crear y asignar estos cupos debe cumplir como las condiciones que le impone la Corte Constitucional en Sentencia T-441 de 1997 cuando establece: "deben ser pocos cupos y tener un buen rendimiento académico, para culminar sus estudios. De alli que resulte de gran importancia garantizar que los estudiantes admitidos a través de las vías especiales reúnan las condiciones académicas mínimas para poder realizar satisfactoriamente sus estudios. En este aspecto, la universidad está llamada a diseñar fórmulas y mecanismos que faciliten la incorporación a la vida universitaria de los alumnos admitidos a través de los mecanismos especiales"

Corresponde ahora preguntar si los deportistas en Colombia pueden ser considerados o no como población especial para tener la posibilidad de ser incluidos en los grupos poblacionales vulnerables tenidos en cuenta, bajo argumentos razonables, para la adjudicación de cupos especiales.

En principio se podría afirmar que esta estrategia pedagógica debería ser considerada por las universidades e incluir a los deportistas como población especial para acceder a estos limitados cupos; sin embargo, a pesar de que el artículo 52 de la Carta Política impone al Estado la obligación de promover y garantizar los derechos a la recreación y el deporte, ello, no significa que asuma el deber de proponer a las universidades asignar cupos especiales a esta población.

Sostiene la Corte Constitucional en la Sentencia T-441 de 1997 que:

...el hecho de que la universidad deba comprometerse con la promoción del deporte no constituye una razón suficiente para crear un cupo especial para favorecer el acceso de los deportistas a los estudios superiores. Si bien no se niega que la presencia en la universidad de deportistas de alto rendimiento puede constituir un estímulo para la práctica de las actividades de recreación física, este objetivo puede lograrse a través de medidas menos lesivas de los intereses de los otros aspirantes a acceder la universidad. El impulso de las actividades deportivas bien puede realizarse a través de medidas distintas, que no impliquen el sacrificio injusto y excesivo de la aspiración de algunas personas de realizar estudios superiores. Además, en las condiciones actuales del país, la imposición de esa carga sobre estos individuos aparece como inaceptable, en razón del hecho de que, por lo regular, las actividades de alta competencia deportiva y las académicas se desarrollan en esferas diferentes y distantes. Con fundamento en los anteriores argumentos, este cupo especial será declarado como inconstitucional y se ordenará su inaplicación.

El problema jurídico planteado en el presente trabajo que así resuelto: es claro que una persona por el hecho de ser deportista no tiene una diferenciación 
frente a los demás aspirantes para tener acceso a un cupo universitario, pues como lo sustenta la sentencia tal fortaleza no es una razón suficiente para que sea diferenciada de los demás. A pesar de ello aclara la Corte Constitucional que las universidades si deben contar con mecanismos para la implementación del deporte mediante incentivos académicos. Otorgar cupos a deportistas por tener esta calidad vulneraría el derecho a la igualdad.

\section{CONCLUSIONES}

- Si bien es cierto el Estado Social de Derecho, promueve como derechos la educación y el deporte, ni la Constitución Política, ni la Ley ni el desarrollo de la jurisprudencia constitucional ofrecen mecanismos jurídicos idóneos que articulen, mediante estímulos académicos, el derecho al Deporte con el derecho a la educación superior.

- Aunque la Constitución Política otorga a lasuniversidades el derecho a la Autonomía, este no es absoluto. Su desarrollo, alcances y limitaciones deben estar definidos por la Ley.

- La jurisprudencia constitucional es reiterativa al señalar que la autonomía universitaria no puede consolidarse como una "isla jurídica", ya que podría atentar contra otros principios constitucionales, como el principio de la igualdad. Sin embargo, le corresponde al legislador, respetar y proteger el núcleo esencial del derecho al momento de reglamentar su disfrute.

- El derecho a la igualdad no es simplemente un reconocimiento abstracto y formal del Estado frente a sus asociados. La Igualdad va más allá de la mera legalidad, su goce conlleva otros factores (históricos, sociológicos, económicos, políticos). Se trata de un concepto de equidad, de igualdad entre iguales.

- Aunque las universidades gozan de la potestad de regular los procedimientos para asignar cupos a sus programas y carreras y definir cupos especiales en favor de poblaciones vulnerables, no puede sobrepasar los límites constitucionales $y$, por ello, no le está permitido tener como población especial a los deportistas.

- La decisión de asignar cupos especiales a deportistas es inconstitucional, pues las prácticas deportivas, así tengan el carácter de alto rendimiento o competitividad, no son una razón suficiente para aplicar una desigualdad frente a los demás aspirantes. Los deportistas no se constituyen como una población histórica o sociológicamente vulnerable, como sí lo son los desplazados, las comunidades indígenas 0 las afrocolombianas.

- El Estado reconoce, sin embargo, que los deportistas deben tener un trato especial, no en el sentido de obtener cupos universitarios por ostentar tal calidad, sino apoyo y estímulos por tratarse de personas que llevan alegría y orgullo a la población colombiana.

- Es necesario que las universidades, en ejercicio de sus potestades, realicen programas y regulen estímulos académicos que promuevan y articulen el deporte como parte vital de la educación superior, promoviendo la formación de profesionales integrales con sanas prácticas de salud física y mental.

\section{REFERENCIAS BIBLIOGRÁFICAS}

- López Medina, D. El derecho de los jueces. Bogotá, Editorial Legis, 2006.

- http://www.alcaldiabogota.gov.co/sisjur/normas/ Norma1.jsp?i=4125

- http://www.corteconstitucional.gov.co/relatoria/ 